\title{
ANREL
}
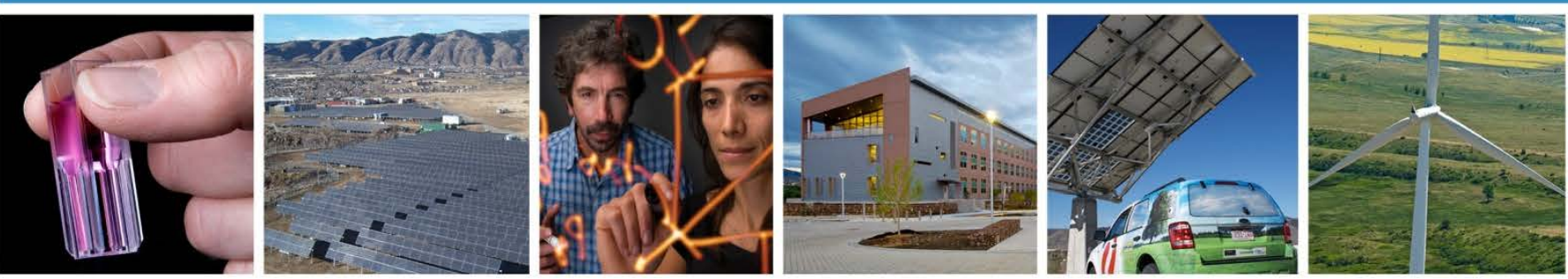

Technical Report

NREL/TP-5400-60949

December 2013

\section{Fall 2013 Composite Data Products - Backup Power}

J. Kurtz, S. Sprik, C. Ainscough, G. Saur, M. Post, and M. Peters 


\section{NOTICE}

This report was prepared as an account of work sponsored by an agency of the United States government. Neither the United States government nor any agency thereof, nor any of their employees, makes any warranty, express or implied, or assumes any legal liability or responsibility for the accuracy, completeness, or usefulness of any information, apparatus, product, or process disclosed, or represents that its use would not infringe privately owned rights. Reference herein to any specific commercial product, process, or service by trade name, trademark, manufacturer, or otherwise does not necessarily constitute or imply its endorsement, recommendation, or favoring by the United States government or any agency thereof. The views and opinions of authors expressed herein do not necessarily state or reflect those of the United States government or any agency thereof.

Available electronically at http://www.osti.gov/bridge

Available for a processing fee to U.S. Department of Energy

and its contractors, in paper, from:

U.S. Department of Energy

Office of Scientific and Technical Information

\section{P.O. Box 62}

Oak Ridge, TN 37831-0062

phone: 865.576 .8401

fax: 865.576.5728

email: mailto:reports@adonis.osti.gov

Available for sale to the public, in paper, from:

U.S. Department of Commerce

National Technical Information Service

5285 Port Royal Road

Springfield, VA 22161

phone: 800.553 .6847

fax: 703.605.6900

email: orders@ntis.fedworld.gov

online ordering: http://www.ntis.gov/help/ordermethods.aspx

Cover Photos: (left to right) PIX 16416, PIX 17423, PIX 16560, PIX 17613, PIX 17436, PIX 17721

Printed on paper containing at least $50 \%$ wastepaper, including $10 \%$ post consumer waste. 


\section{Backup Power Fuel Cell Systems Deployed}

\section{Backup Power Fuel Cell Systems Deployed}

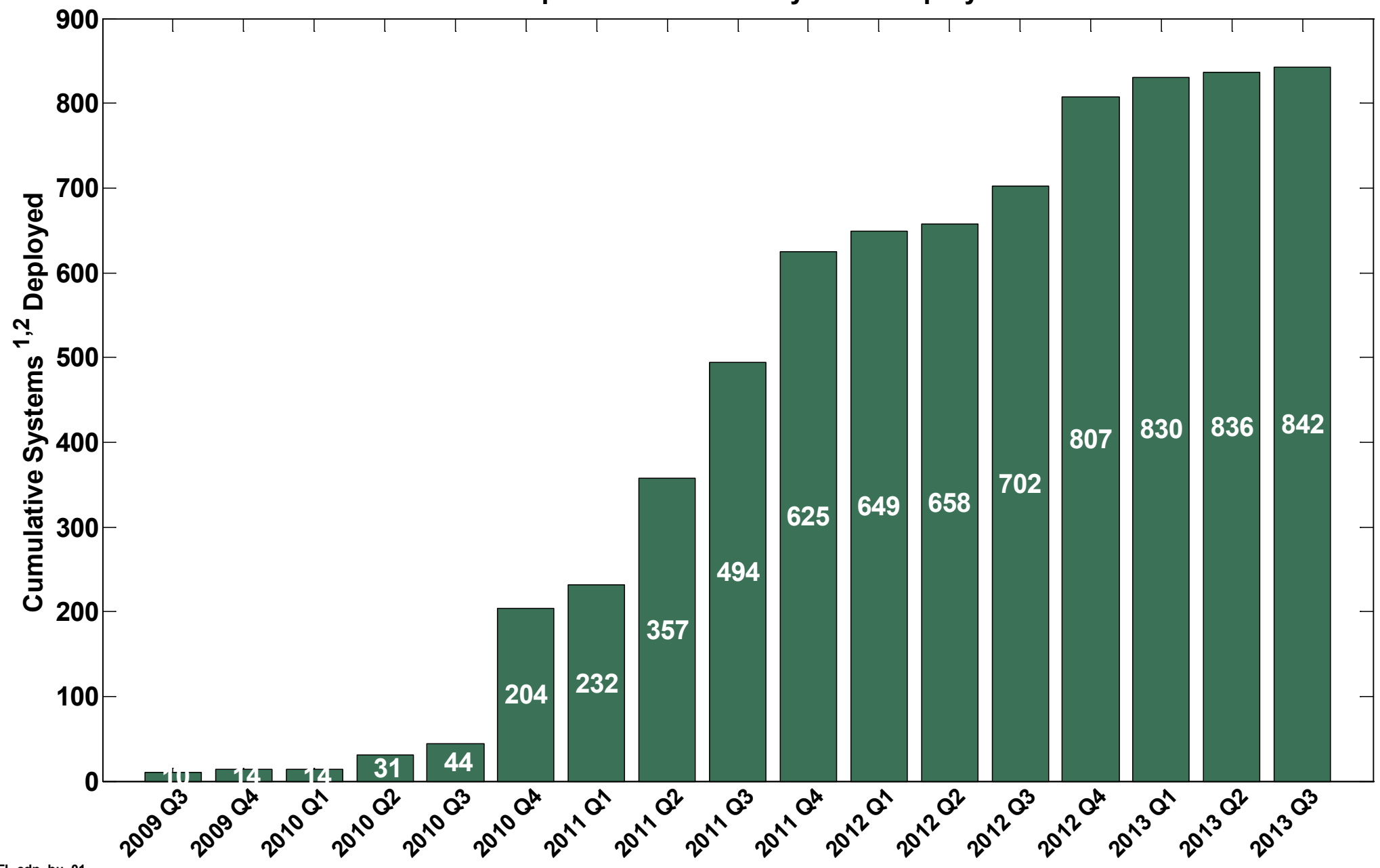

1) Sites may have more than one FC system

2) Not all FC systems are supplying operation data 
CDP-BU-02

\section{Deployed kW Capacity for Backup Power}

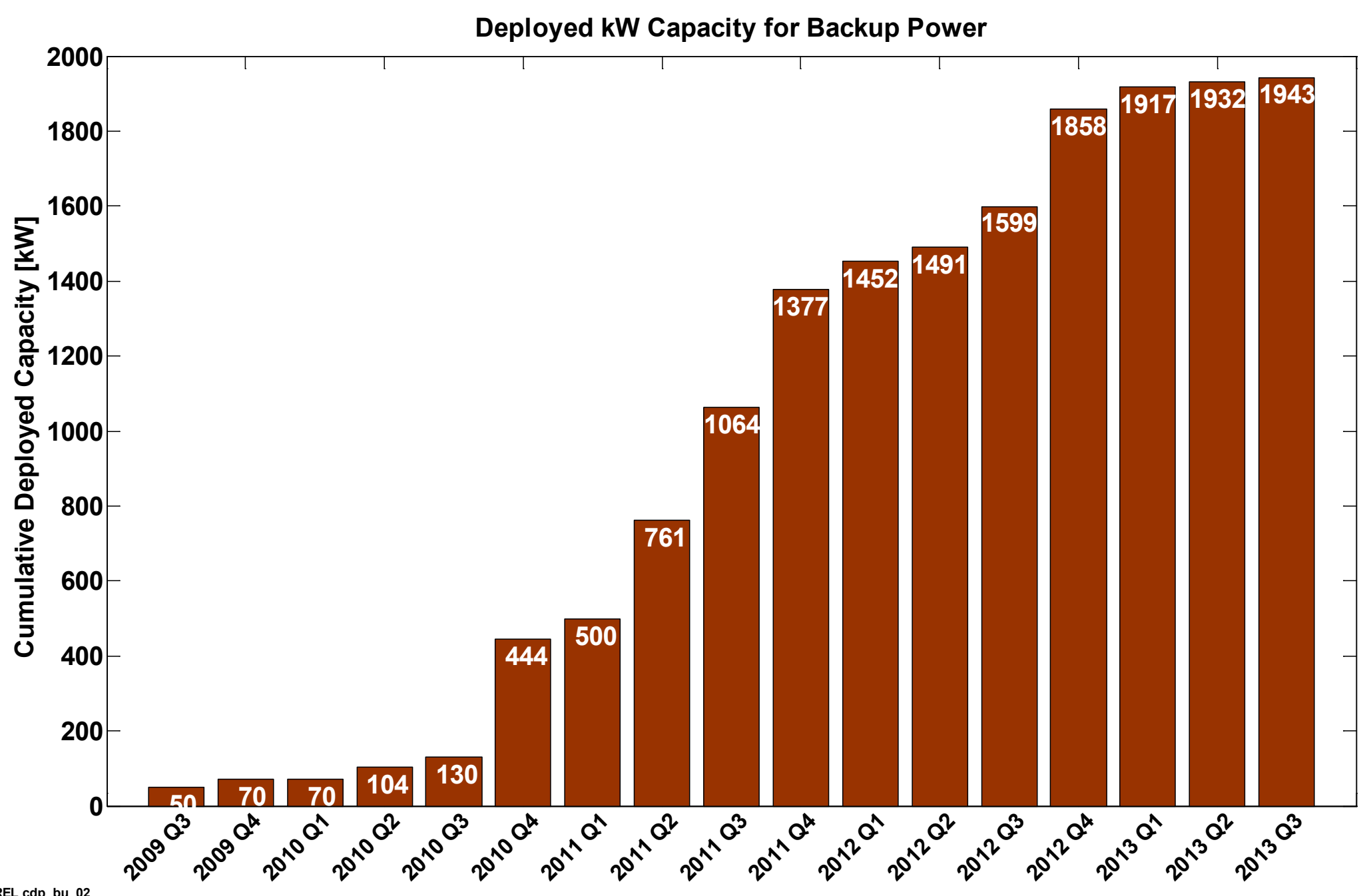

Created: Sep-27-13 1:42 PM | Data Range: 2009Q3-2013Q3 


\section{Backup Power Deployments}

\begin{tabular}{|c|c|c|}
\hline State & $\mathrm{kW}$ & Sites \\
\hline Arizona & 84 & 19 \\
\hline California & 585 & 129 \\
\hline Colorado & 25 & 6 \\
\hline Connecticut & 130 & 28 \\
\hline Florida & 6 & 1 \\
\hline Georgia & 50 & 1 \\
\hline Illinois & 4 & 2 \\
\hline Indiana & 50 & 16 \\
\hline Kentucky & 22 & 4 \\
\hline Louisiana & 40 & 8 \\
\hline Massachusetts & 10 & 1 \\
\hline Michigan & 168 & 41 \\
\hline Mississippi & 10 & 2 \\
\hline Nevada & 2 & 1 \\
\hline New Jersey & 181 & 40 \\
\hline New York & 238 & 55 \\
\hline North Carolina & 10 & 2 \\
\hline Oregon & 2 & 1 \\
\hline South Carolina & 50 & 1 \\
\hline Texas & 238 & 48 \\
\hline Utah & 36 & 9 \\
\hline Washington & 1 & 1 \\
\hline Wyoming & 2 & 1 \\
\hline
\end{tabular}

\section{Backup Power Deployments}

7100
$91-100$
$81-90$
$71-80$
$61-70$
$51-60$
$41-50$
$31-40$
$21-30$
$11-20$
$1-10$

\begin{tabular}{l|l|l|} 
Totals & 1943 & 417 \\
\hline
\end{tabular}

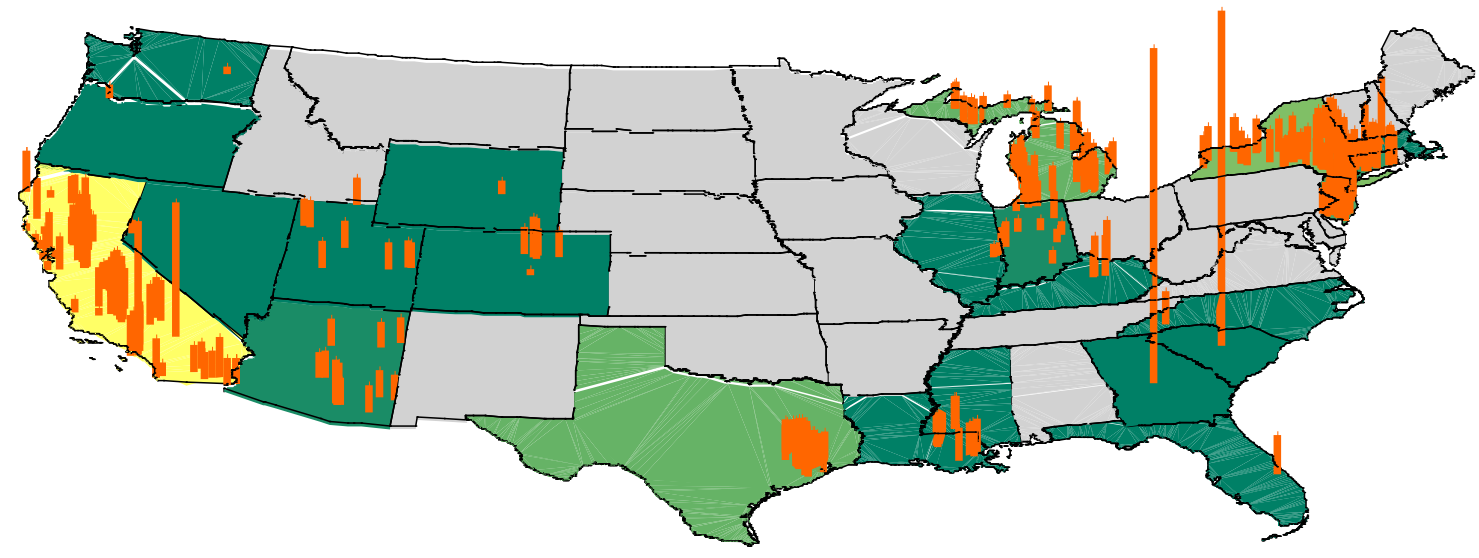

Number of Sites in State

| Site Capacity (line height proporational to installed site kW capacity)

Created: Oct-08-13 2:37 PM | Data Range: 2010Q1-2013Q2 


\section{Starts by Month}

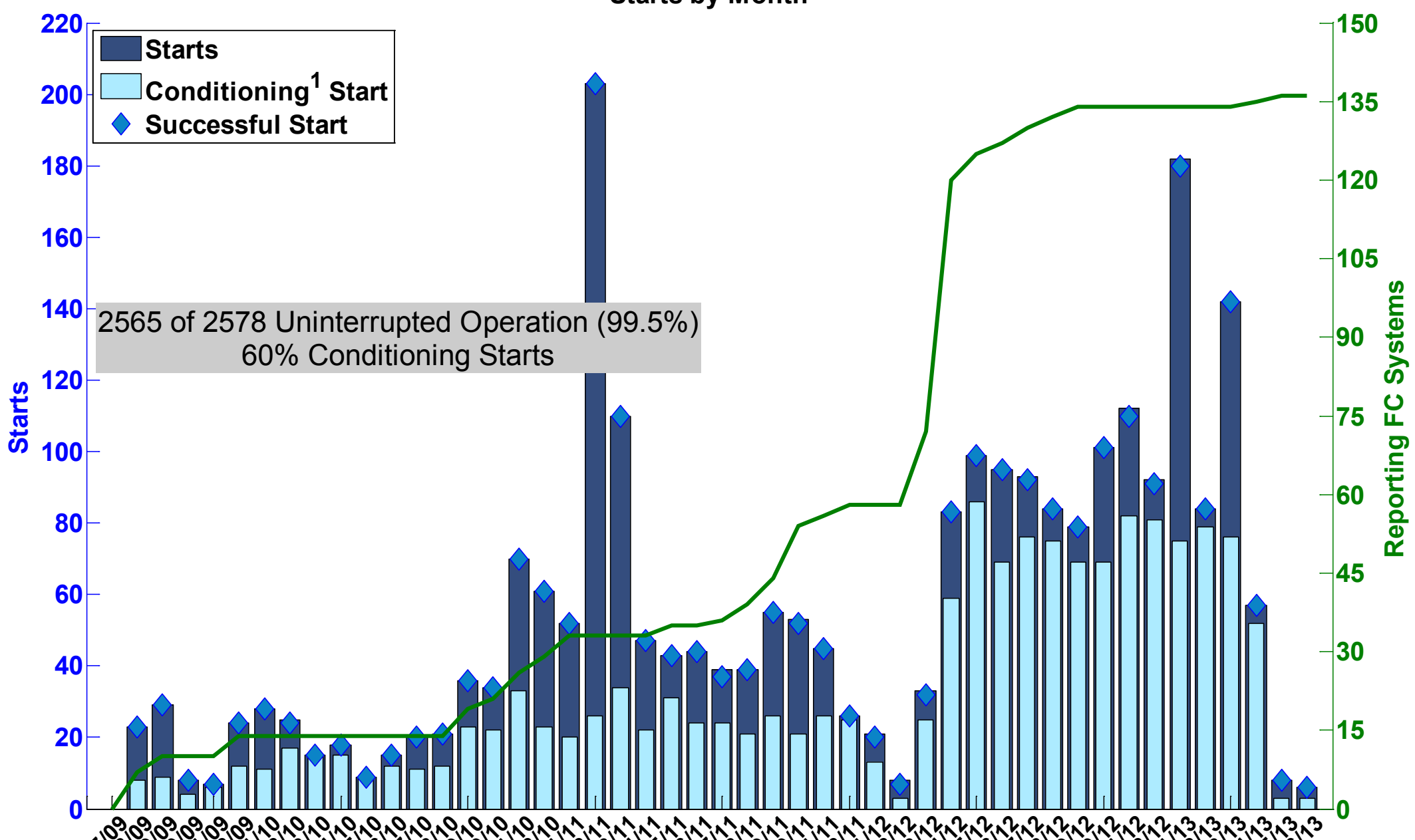




\section{Fuel Cell System Run Hours by Month}

\section{Run Hours by Month}

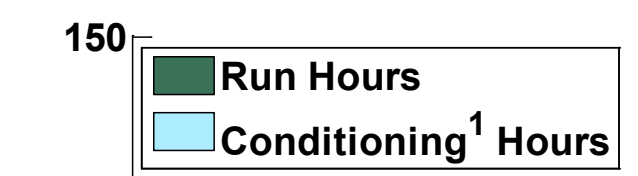

1749 Hours Total Runtime 120 Systems

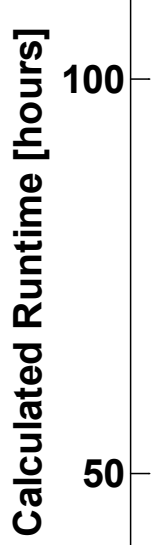

0.8 Hours Average Fleet Runtime

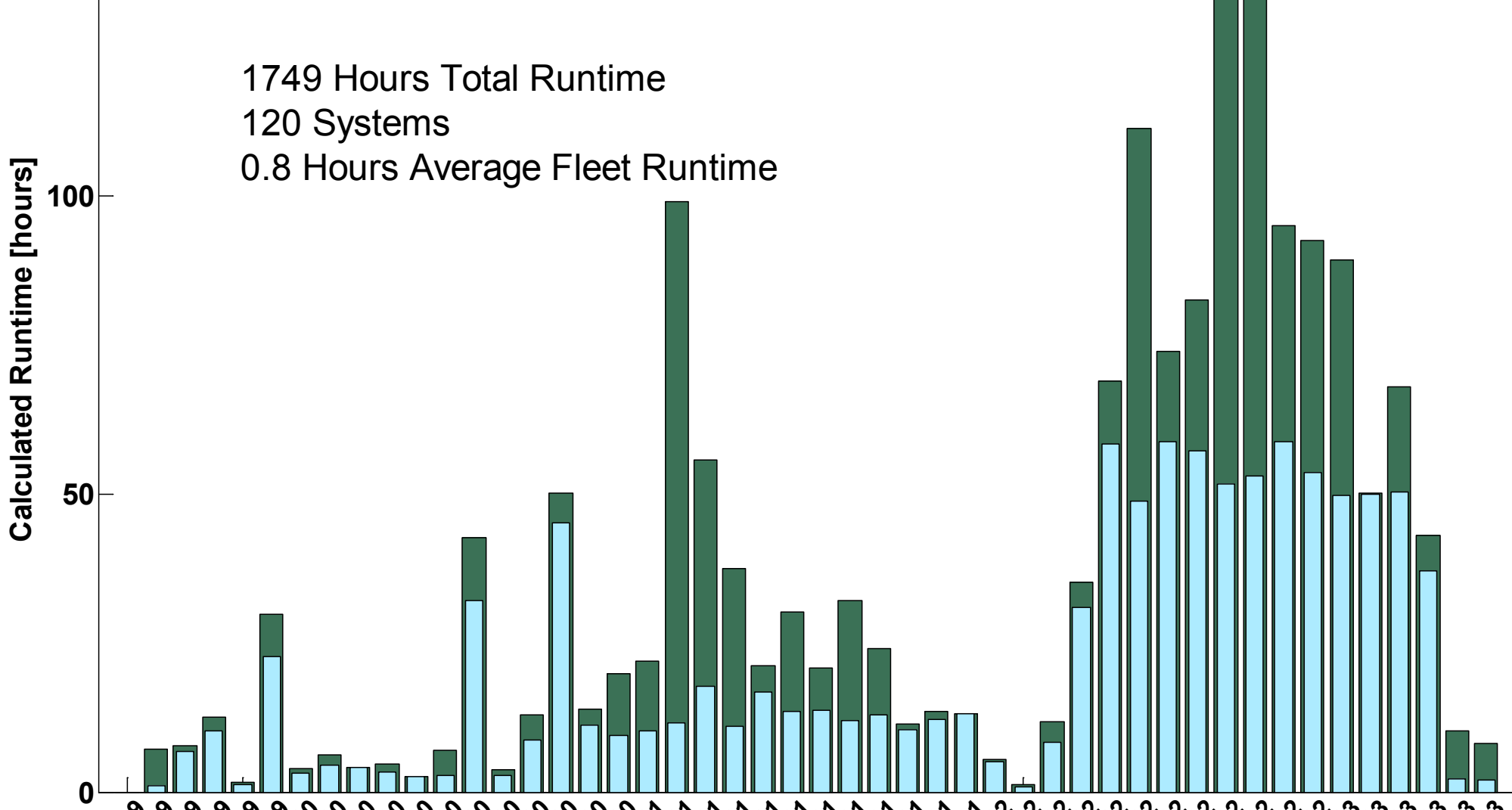

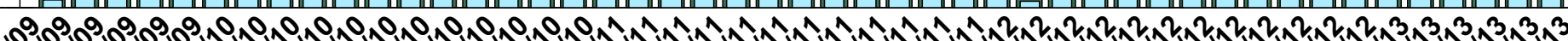

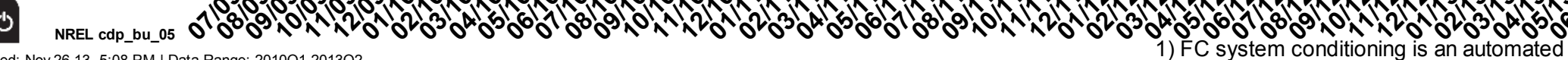




\section{Cumulative Hydrogen Consumed by Month}

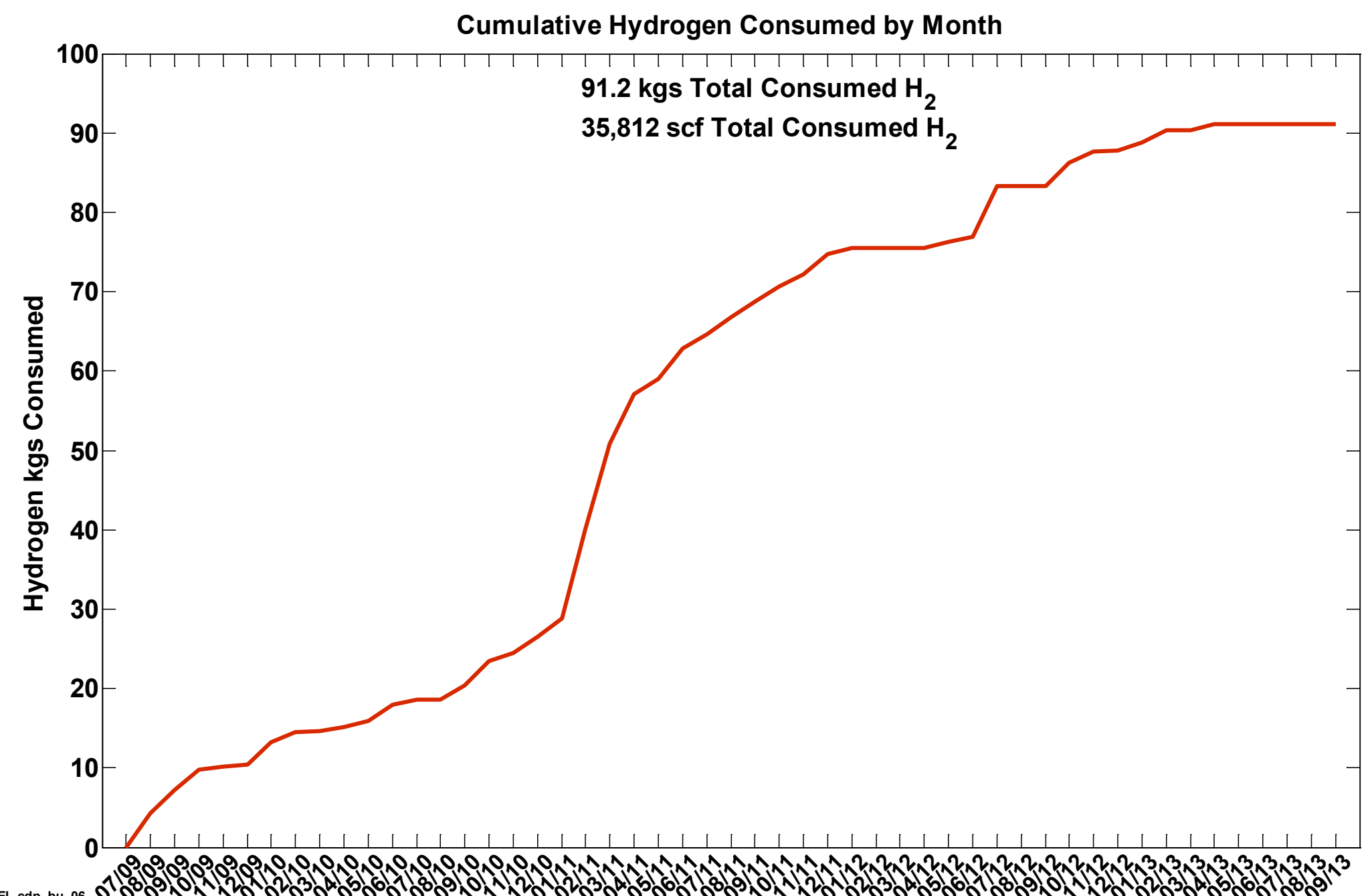




\section{Fuel Cell System Starts by Day of Week}

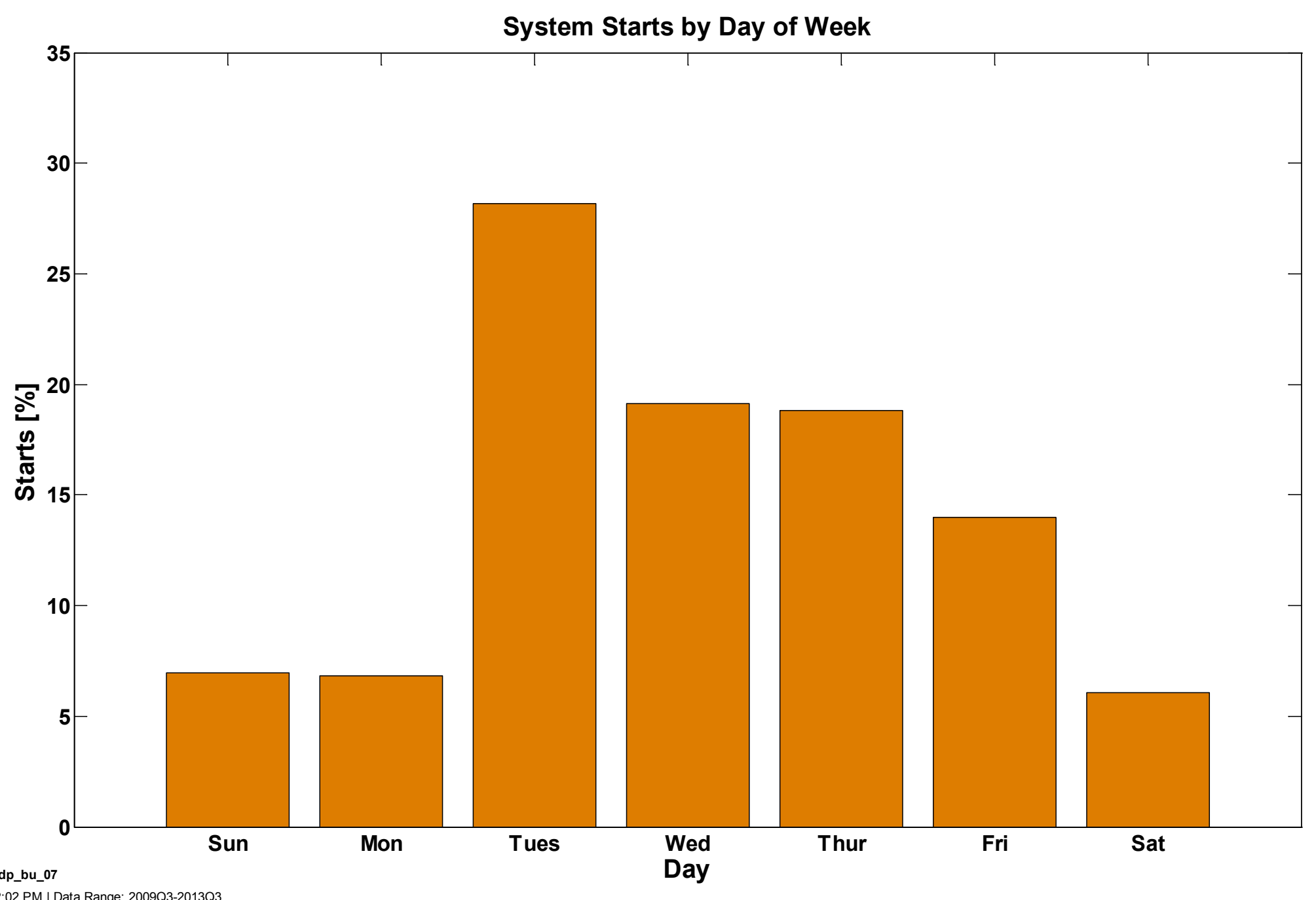




\section{Fuel Cell System Starts by Time of Day}

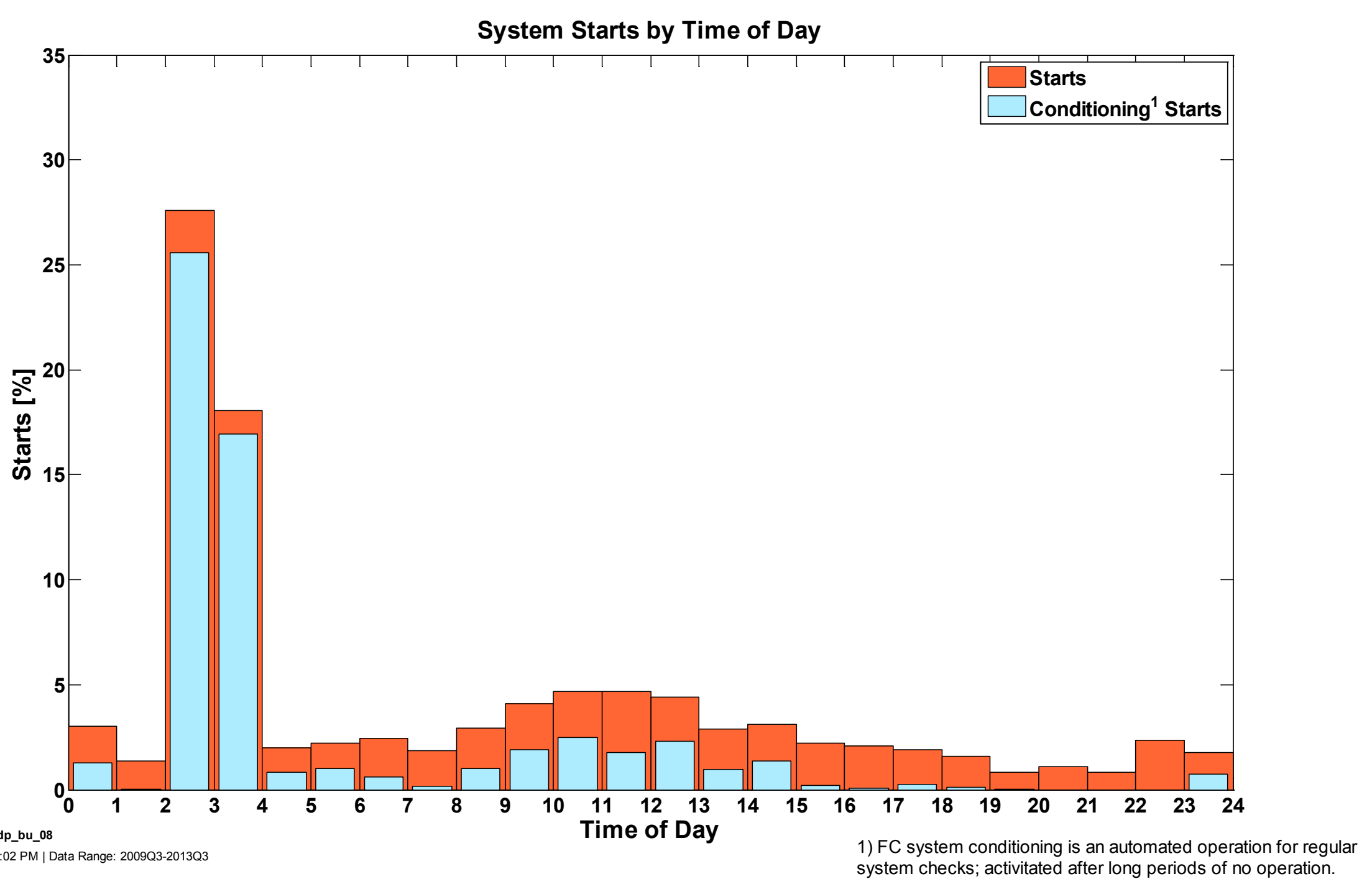




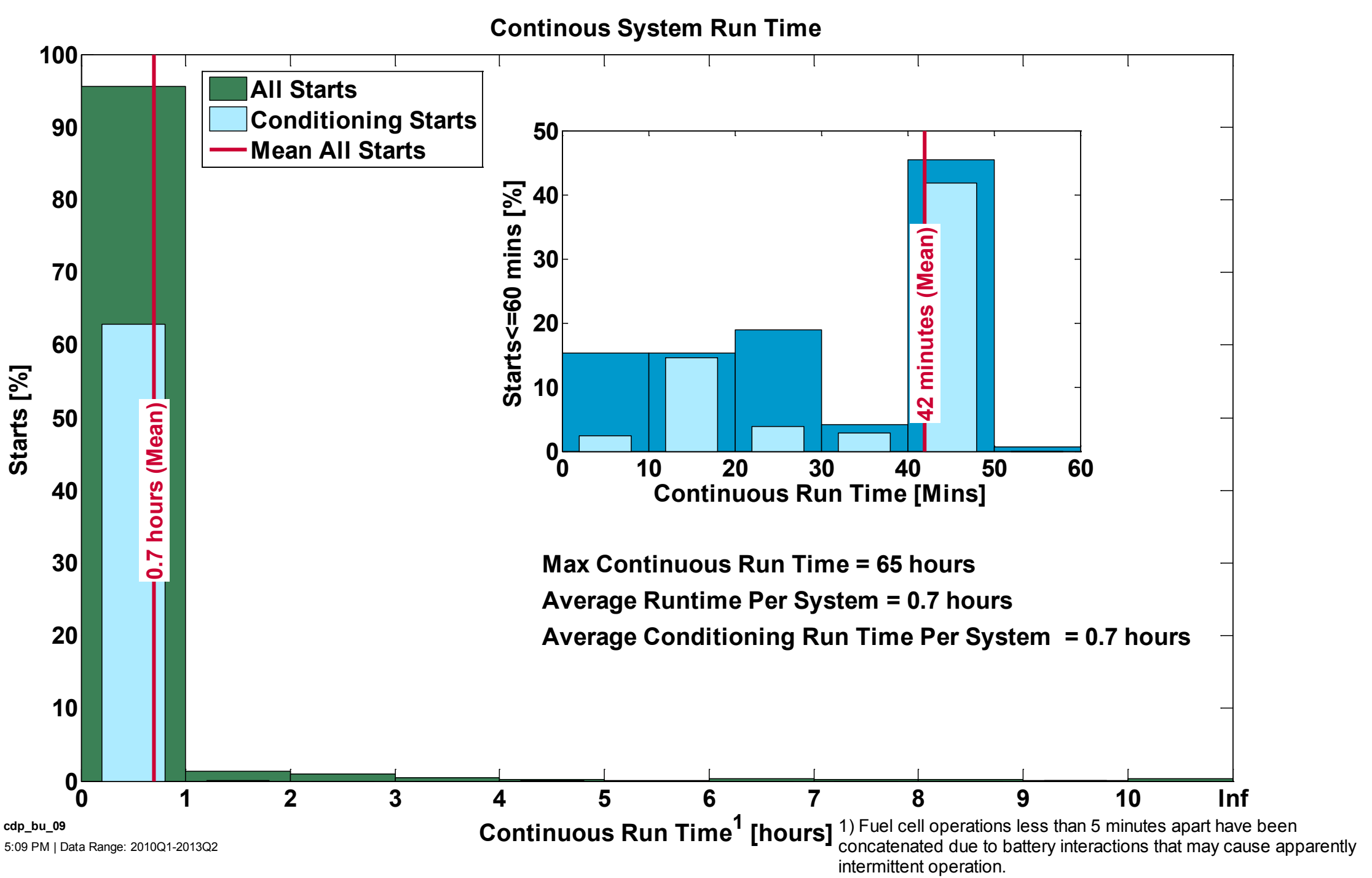




\section{Interrupted Operation Categories}

Uninterrupted Operation Interrupted Operation Categories

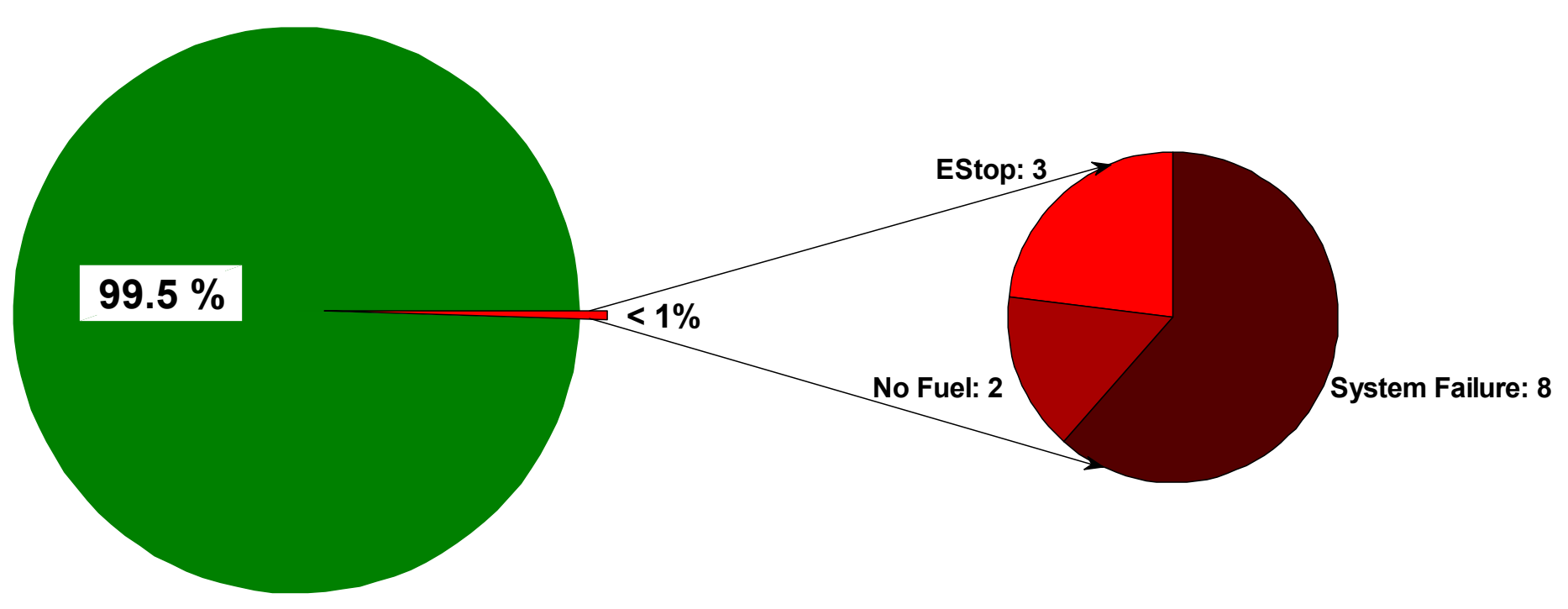

2565 out of 2578 uninterrupted operation

13 interrupted operations

1 NREL cdp_bu_10

Created: Nov-26-13 5:42 PM | Data Range: 2010Q1-2013Q2 
Time Between Starts

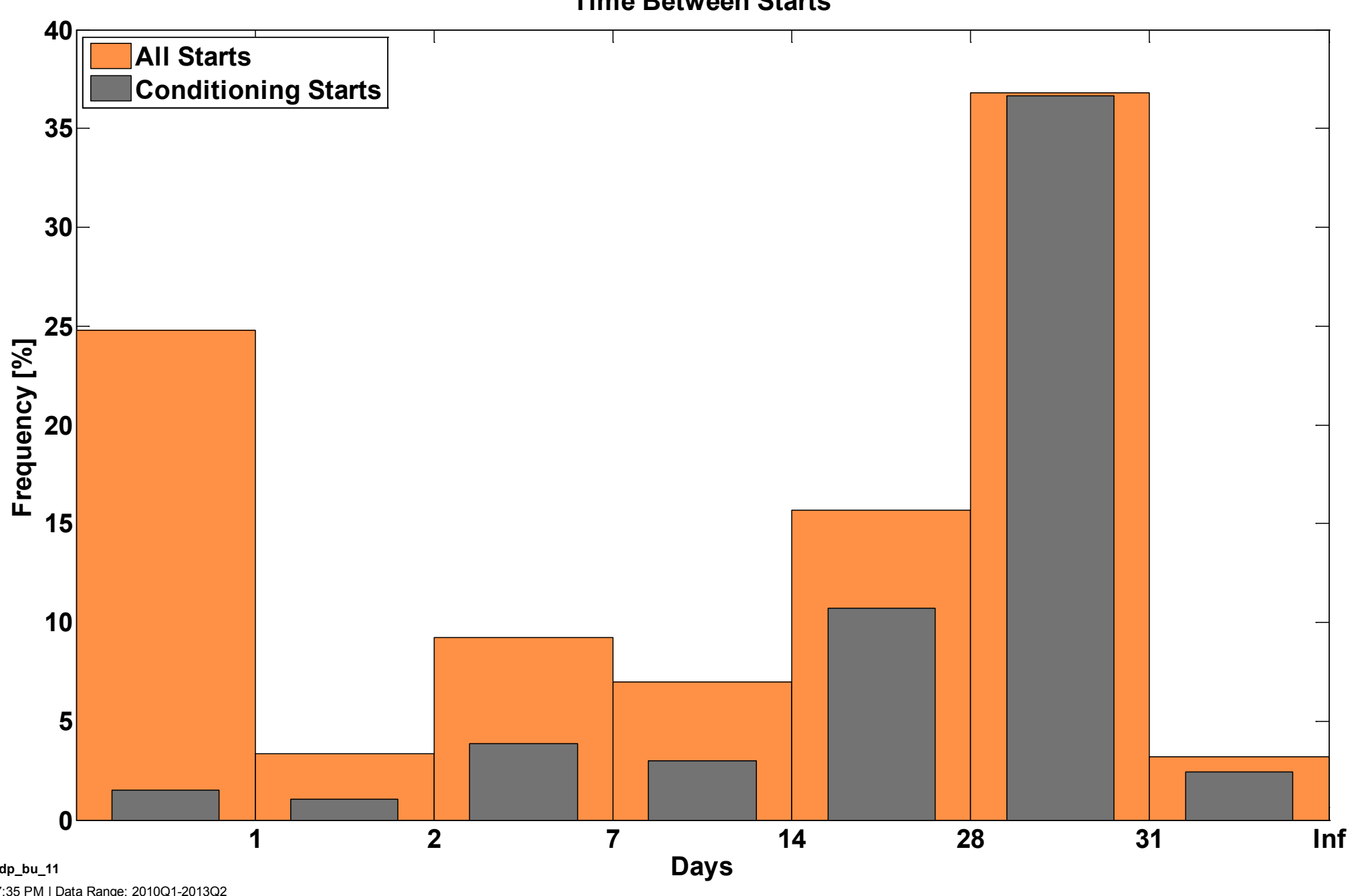

Created: Sep-30-13 7:35 PM | Data Range: 2010Q1-201302 


\section{System Start Ambient Temperature}

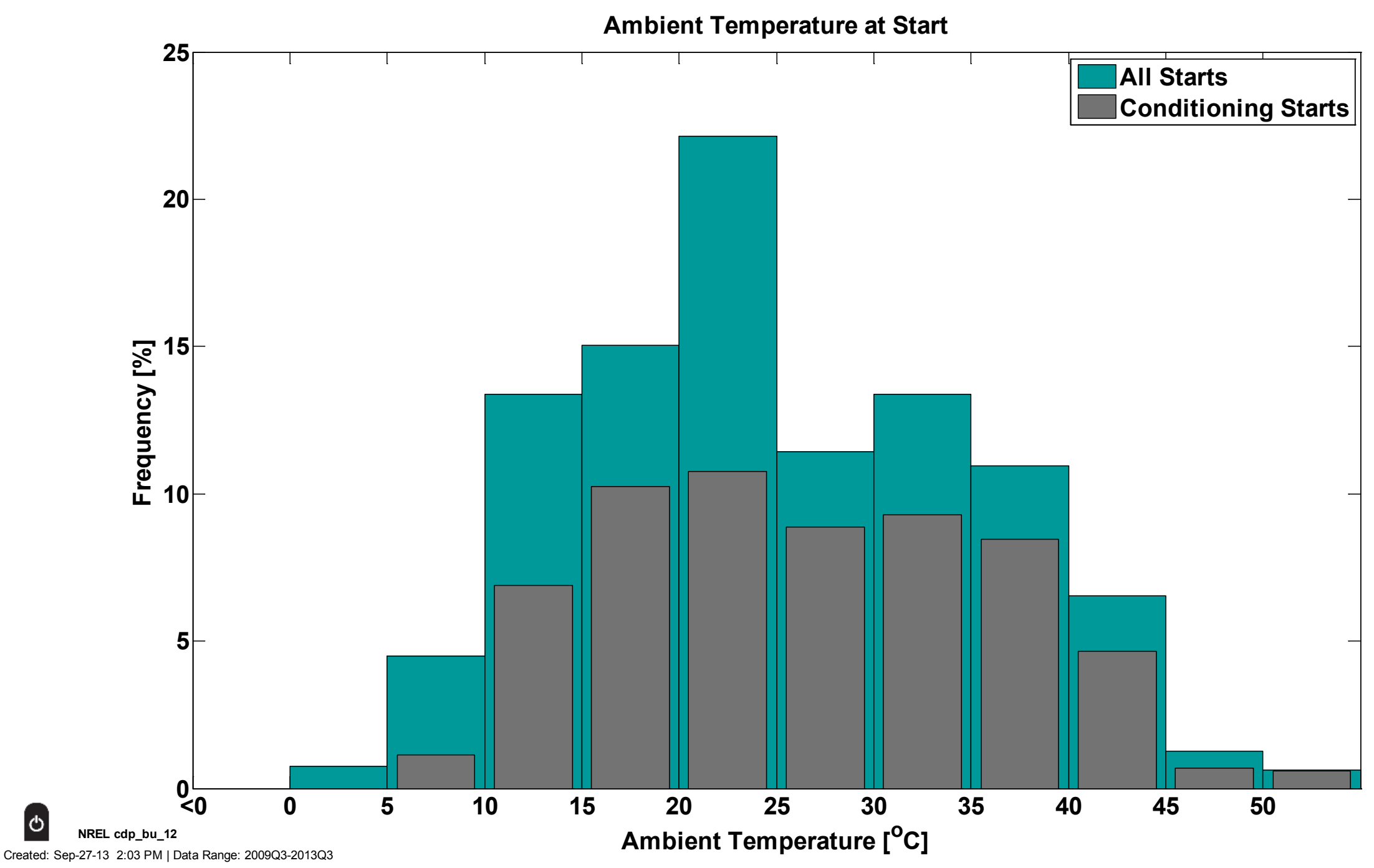




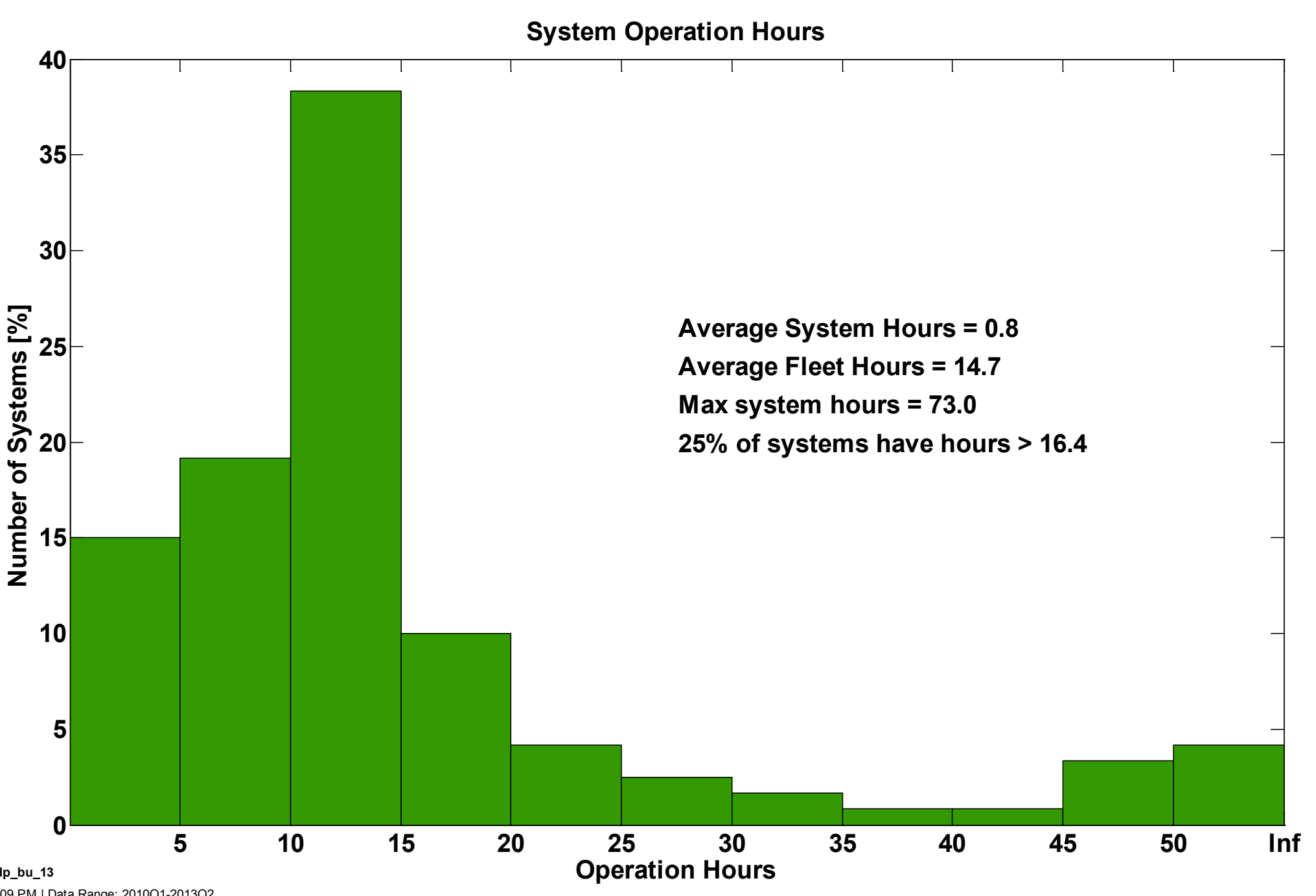




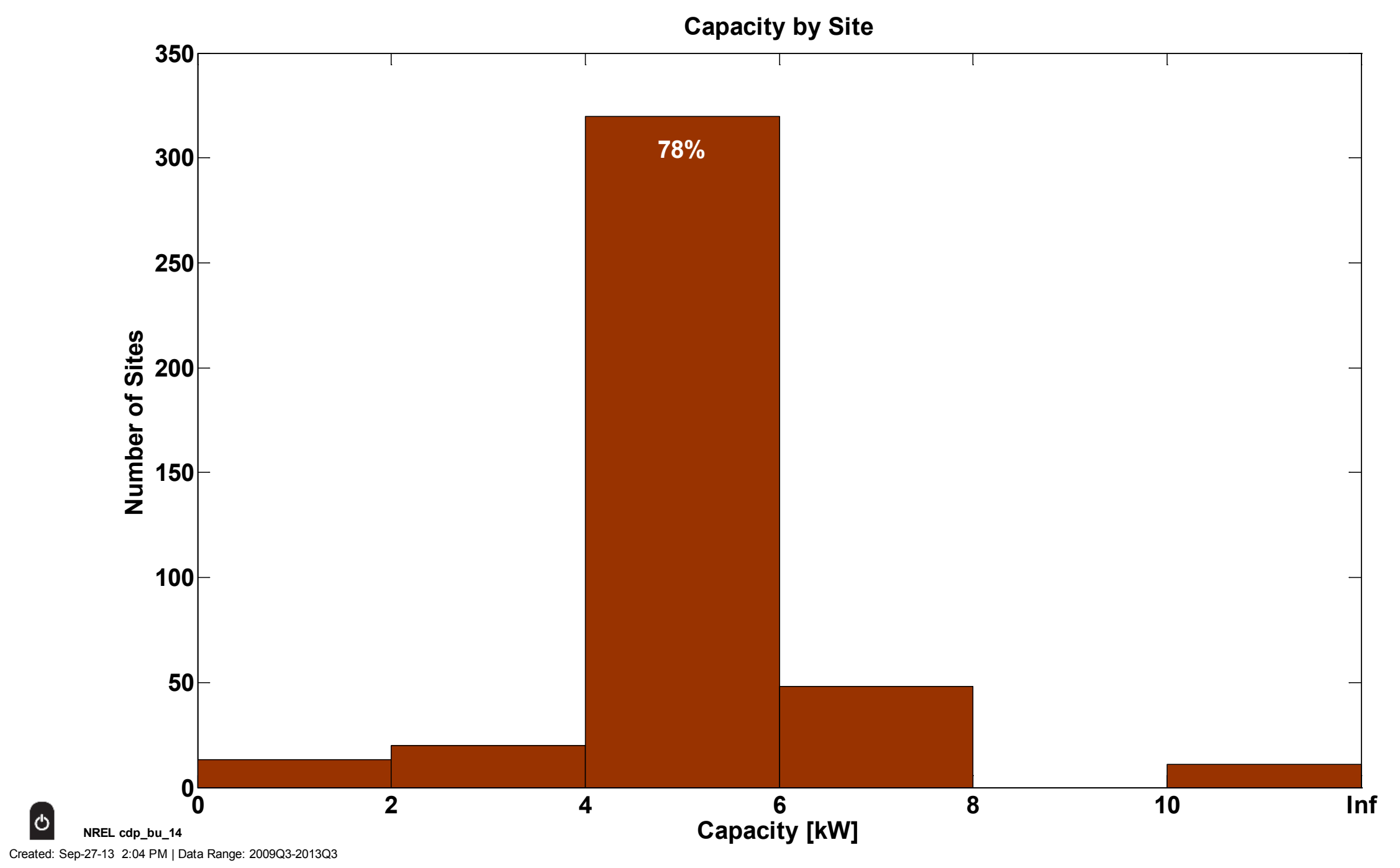




\section{Backup Power Operation With Grid Outage from 01/2010 to 08/2013}

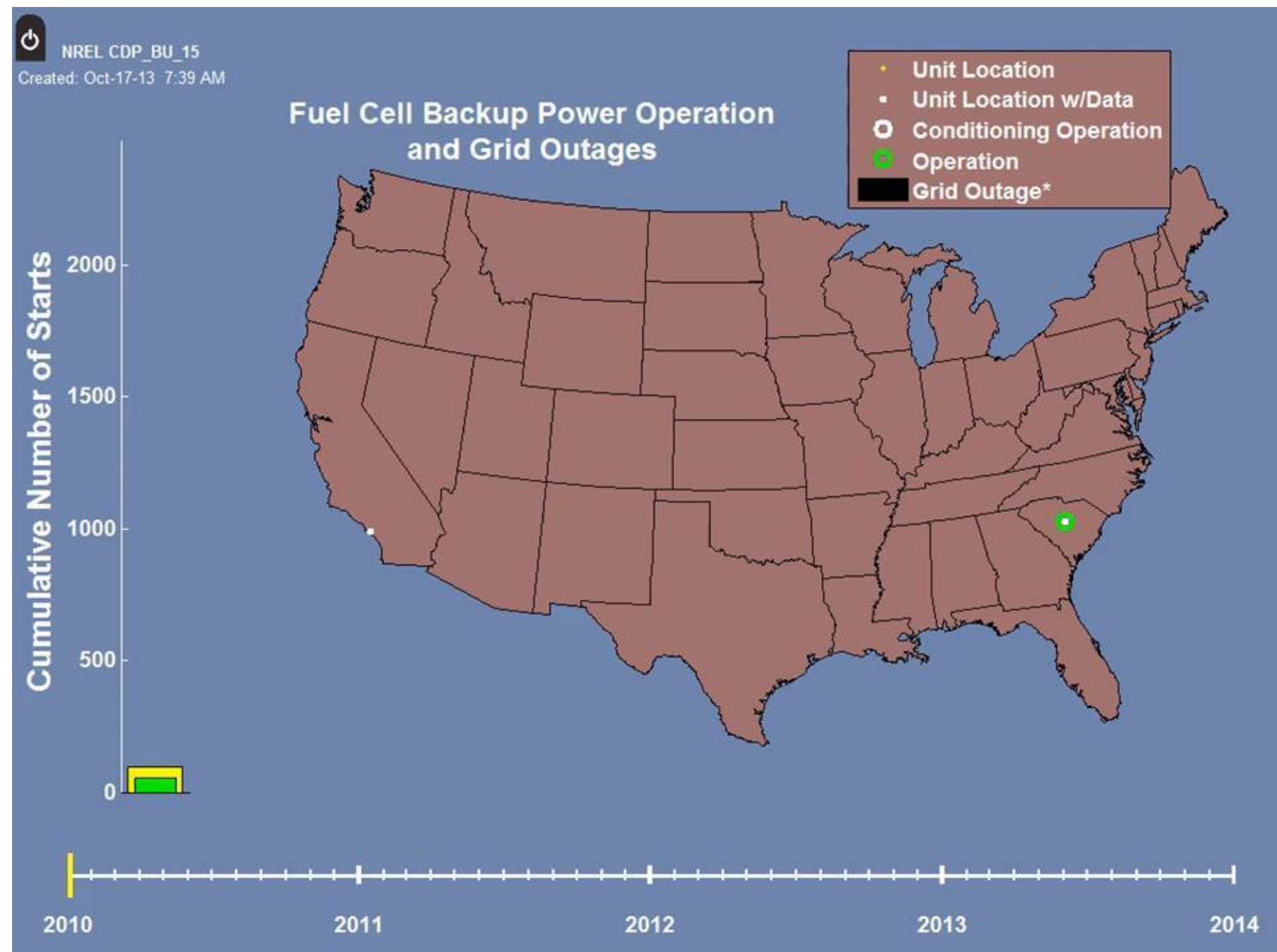




\section{Operation Hours Per Month}

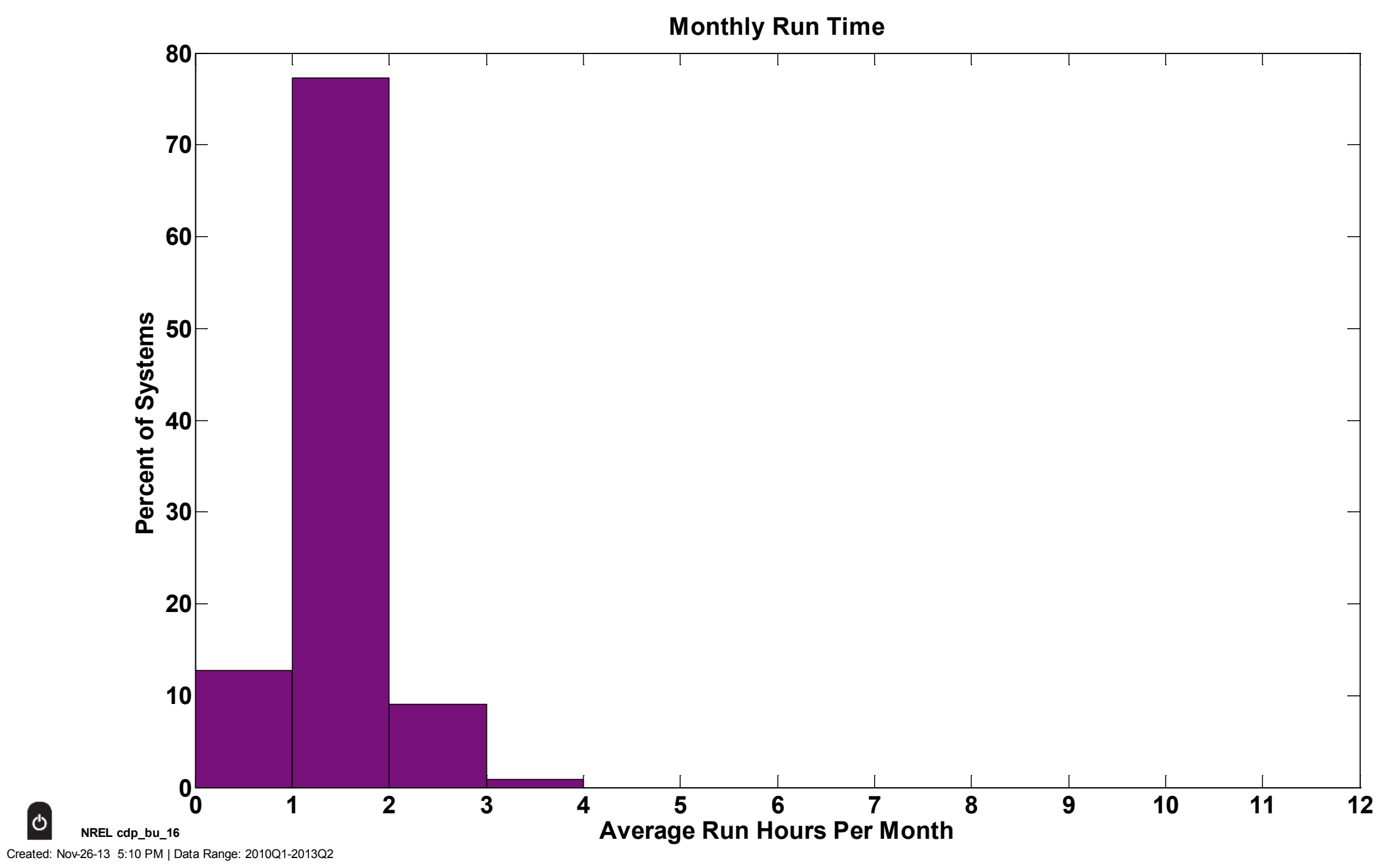




\section{Average Starts Per Month}

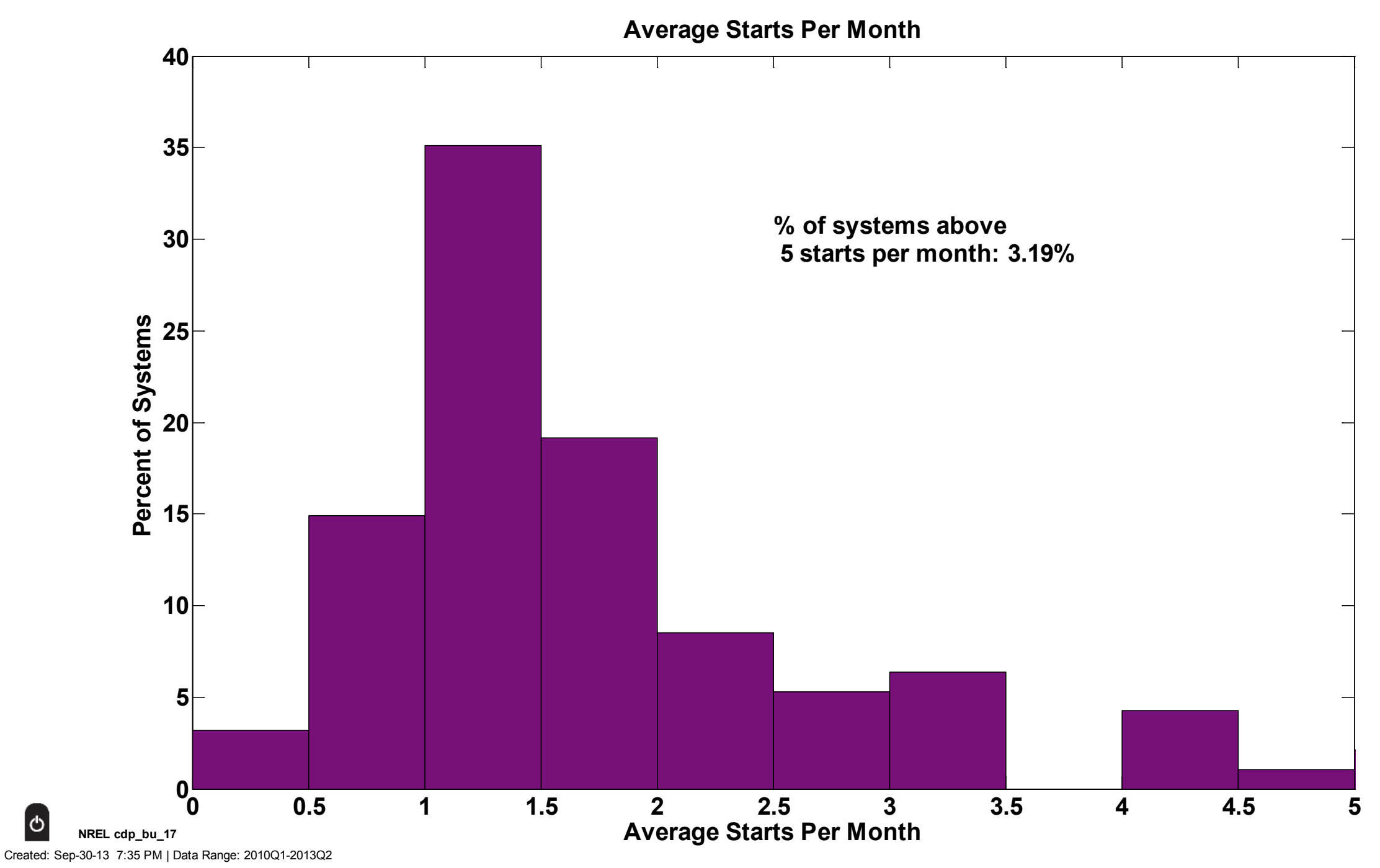




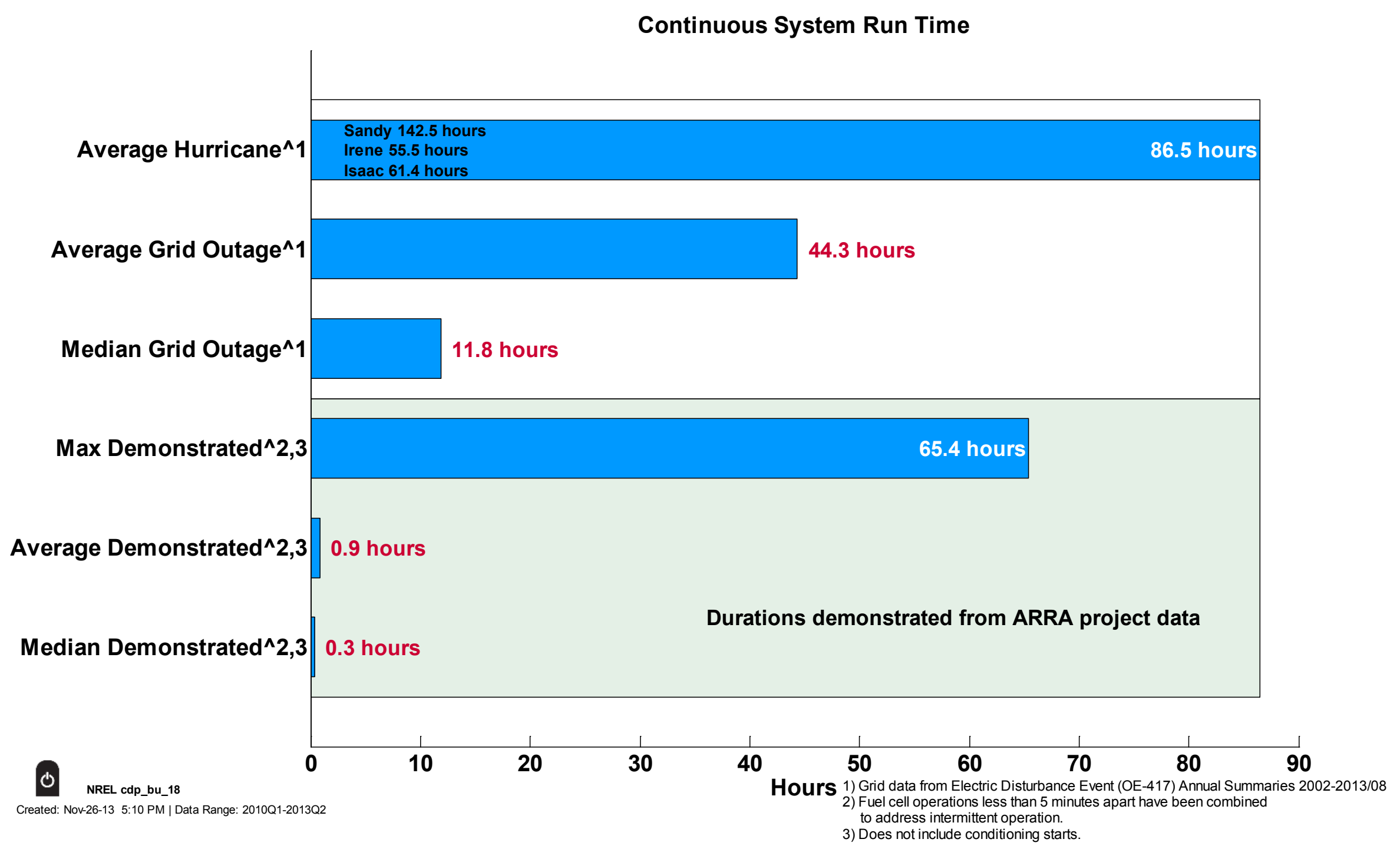




\section{FC Unit Locations - Backup Power}

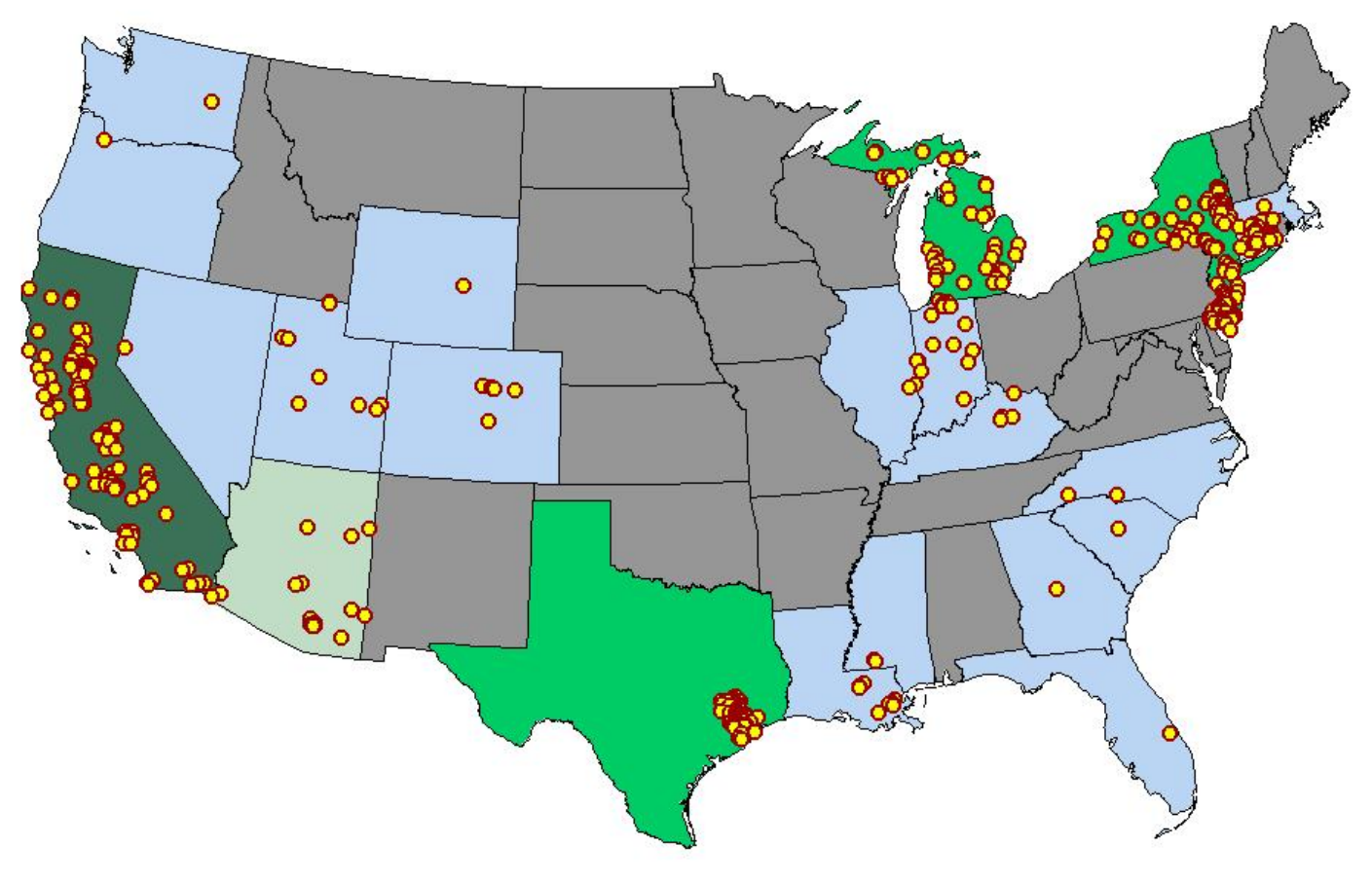

Backup Power (417 Sites and 842 FC Units)

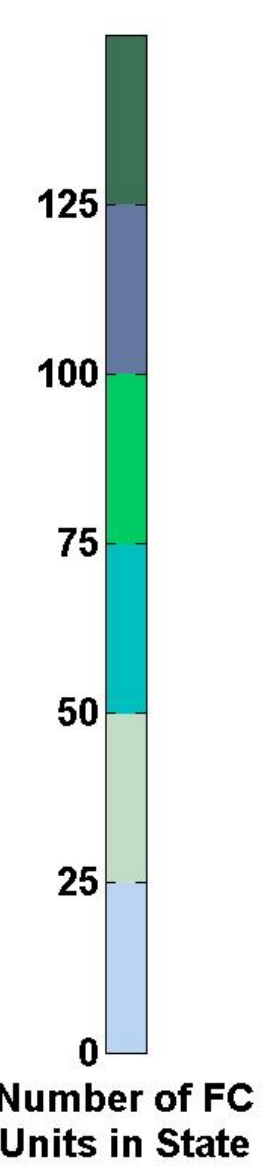




\section{Power Outages per Year}

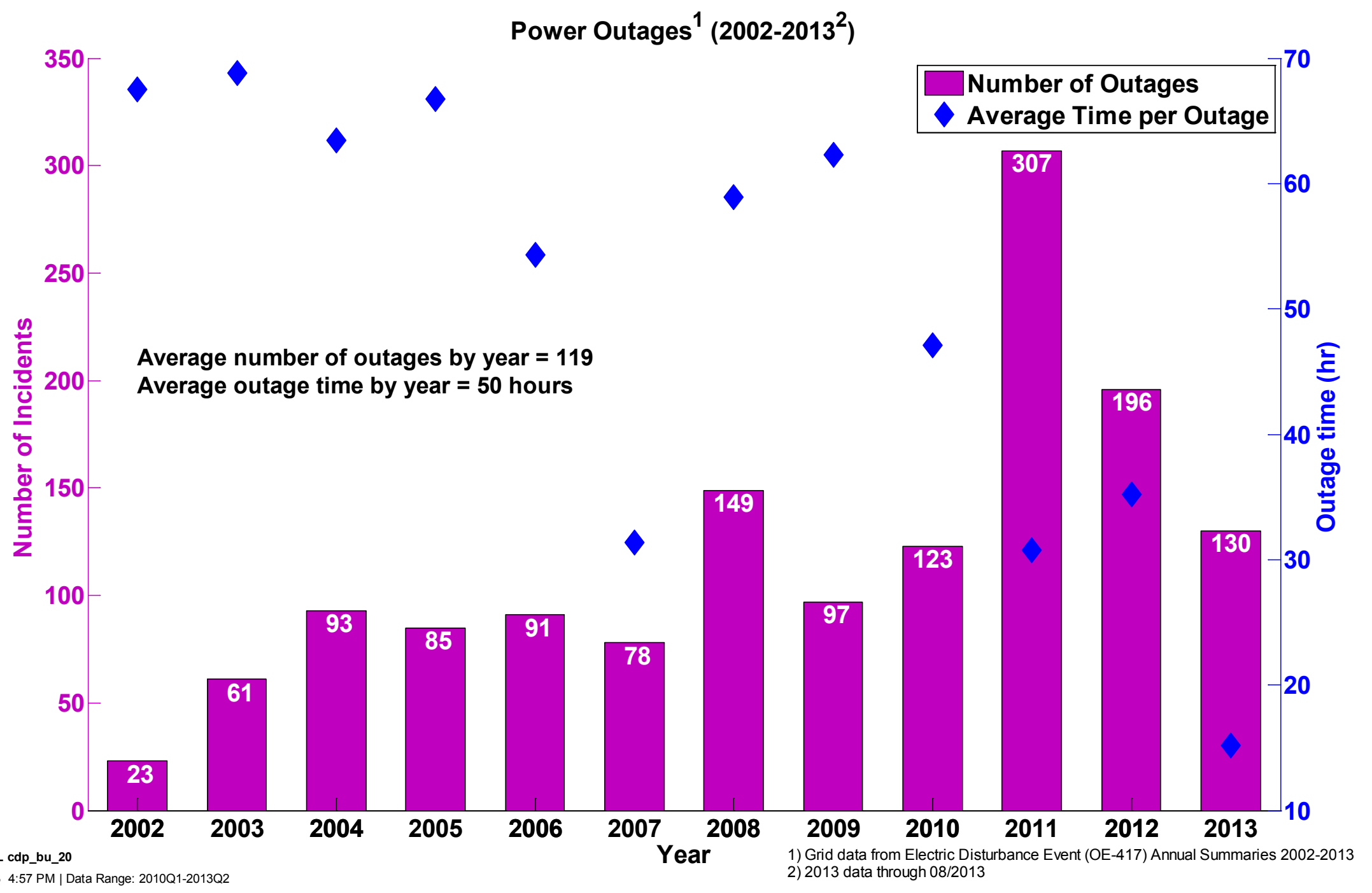




\section{Operation Hours vs. Calendar Days}

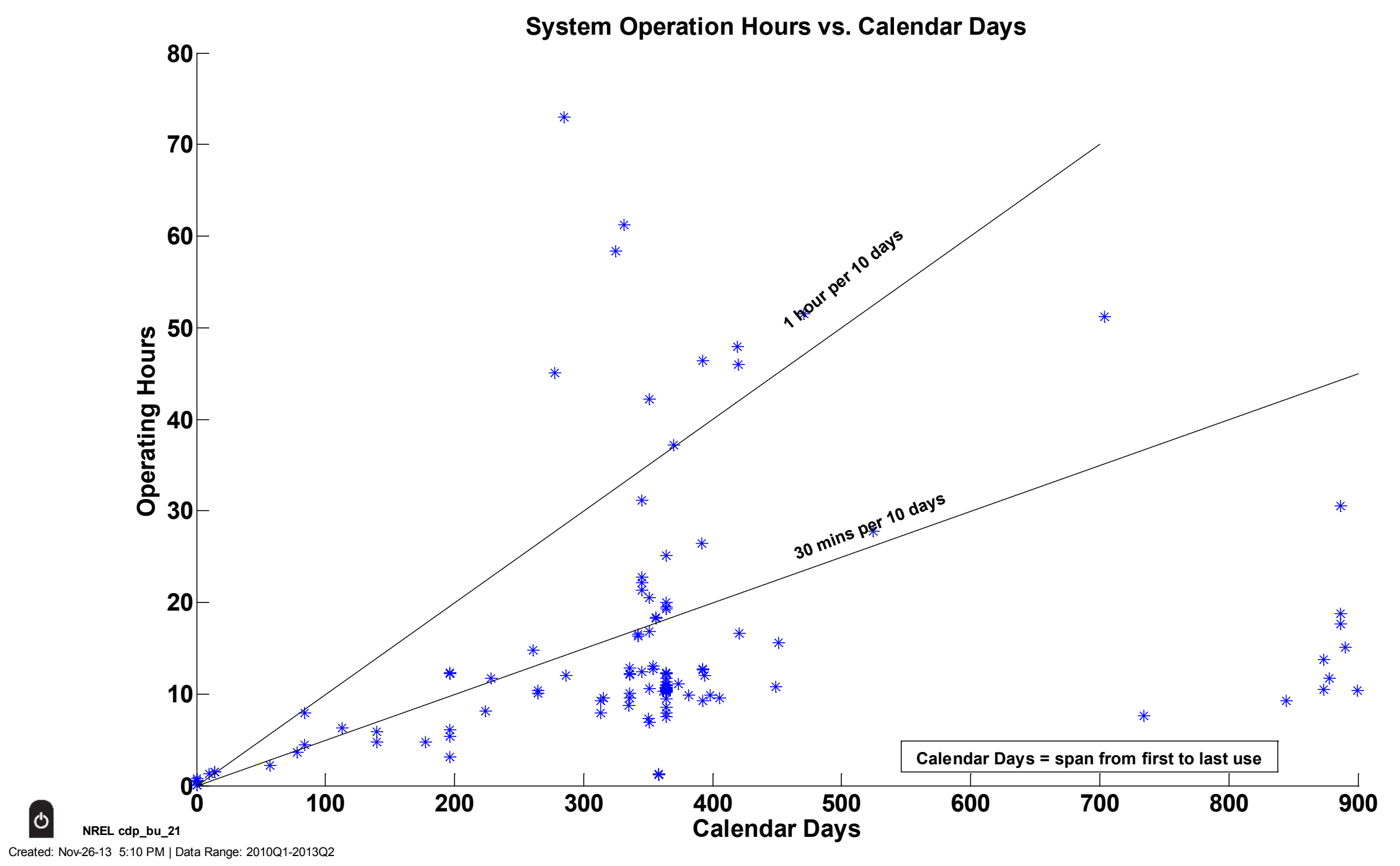




\section{Annualized Cost by Runtime}

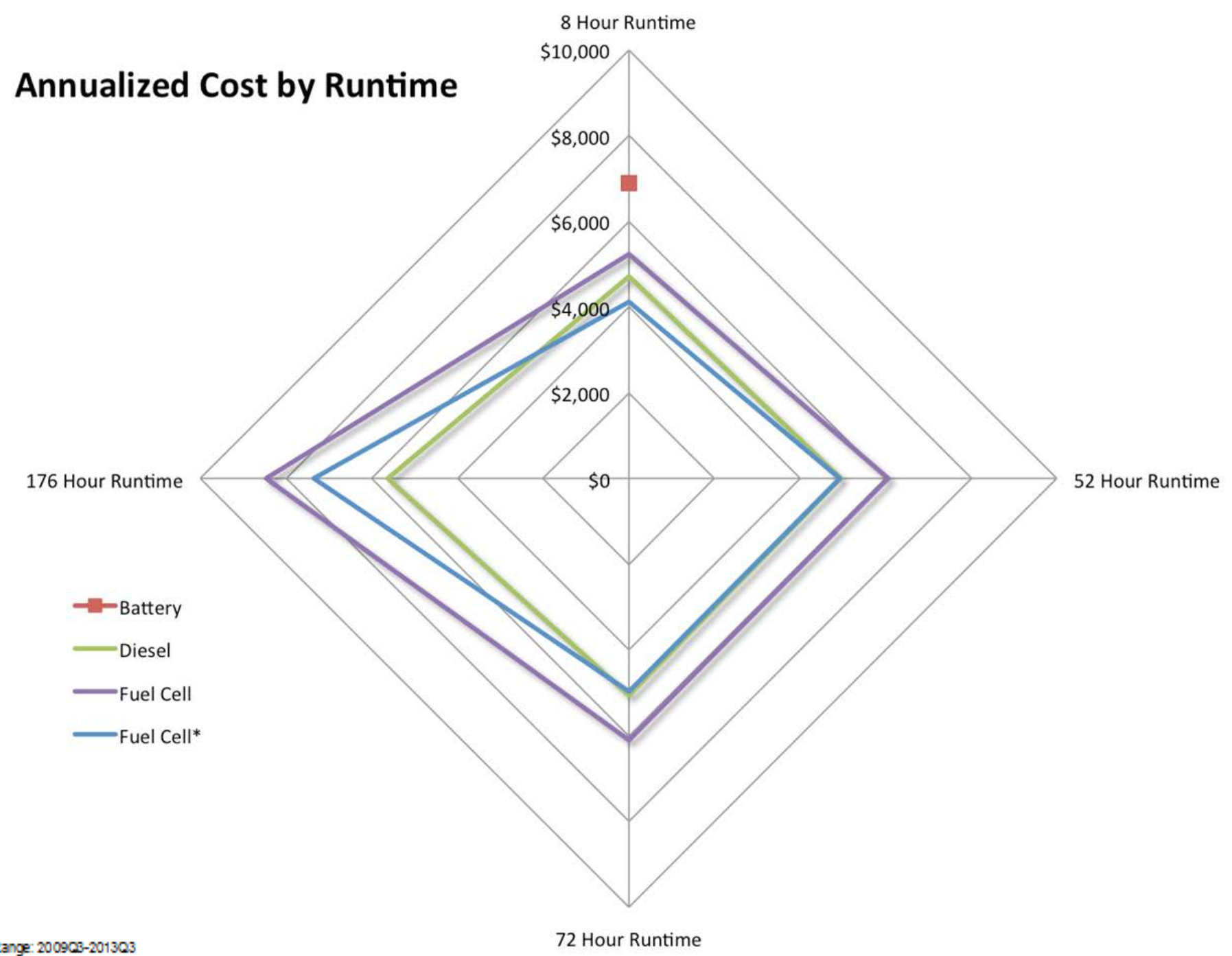




\section{Annualized Cost of Ownership}

\section{Annualized Cost of Ownership for Backup Power}

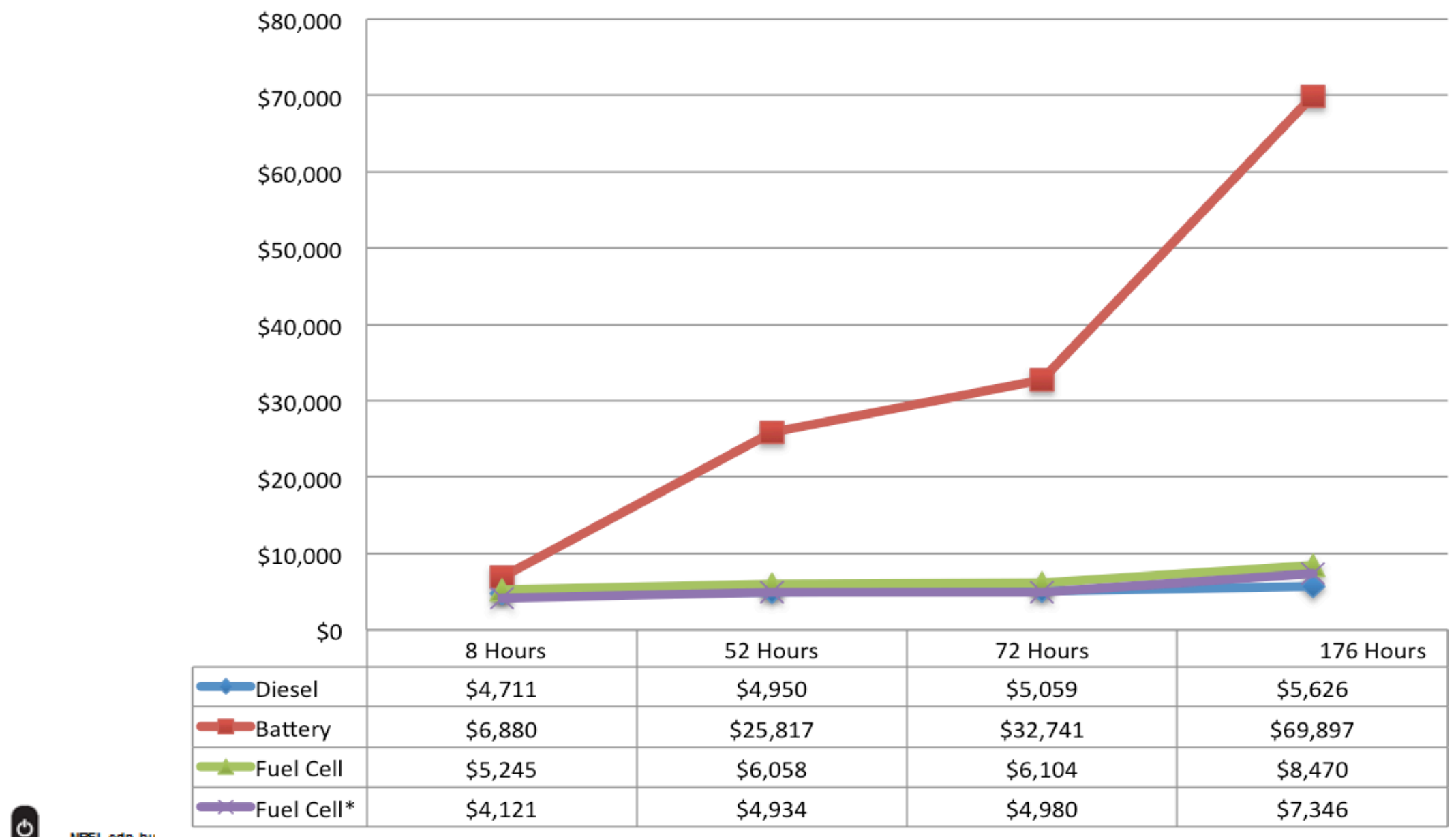

Created: Sep 18 -13 2:14 PM | Data Frange: 200903-2013:23 


\section{8-hour Annualized Cost of Ownership}

\section{8-hour Annualized Cost of Ownership}

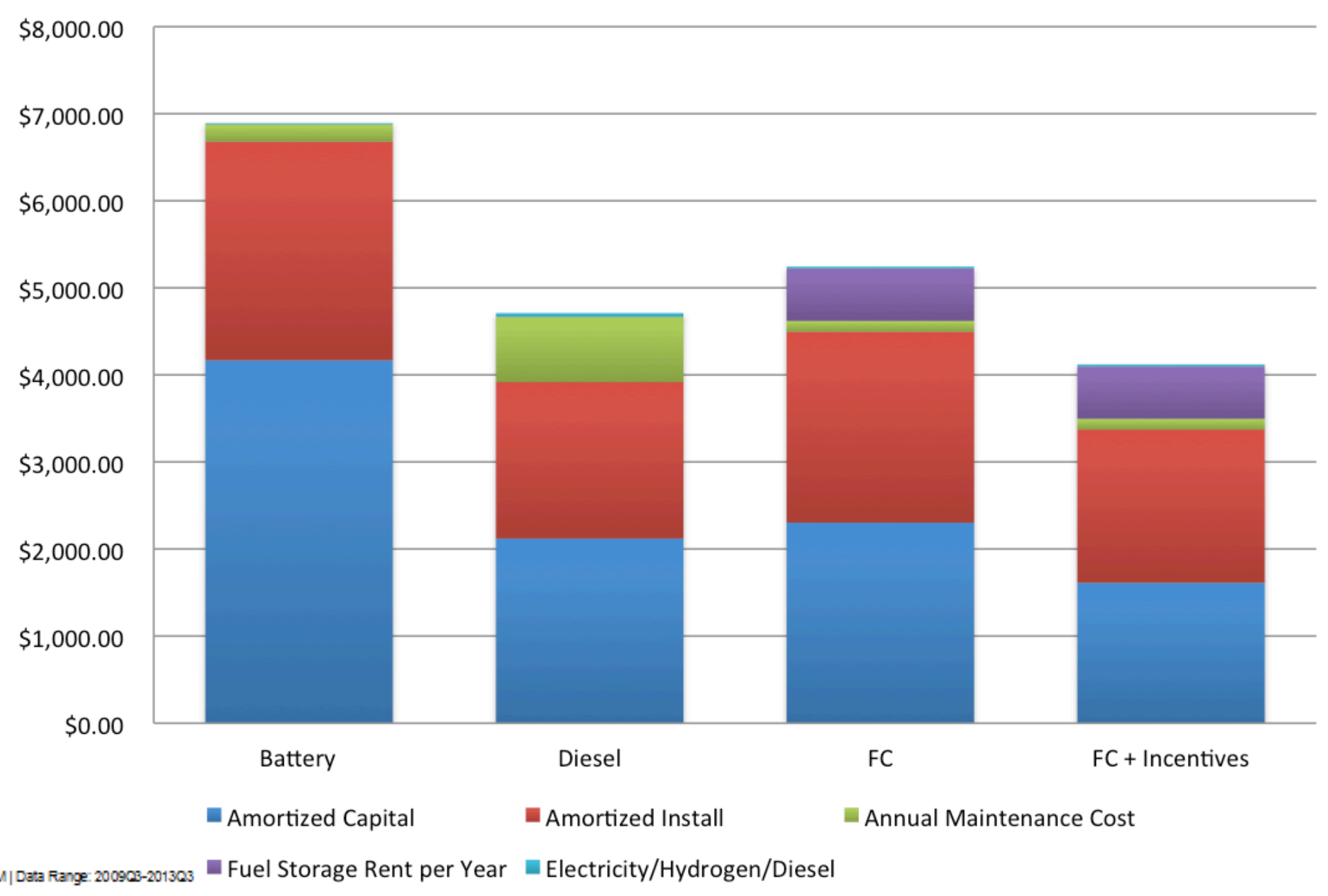




\section{2-hour Annualized Cost of Ownership}

\section{2-hour Annualized Cost of Ownership}

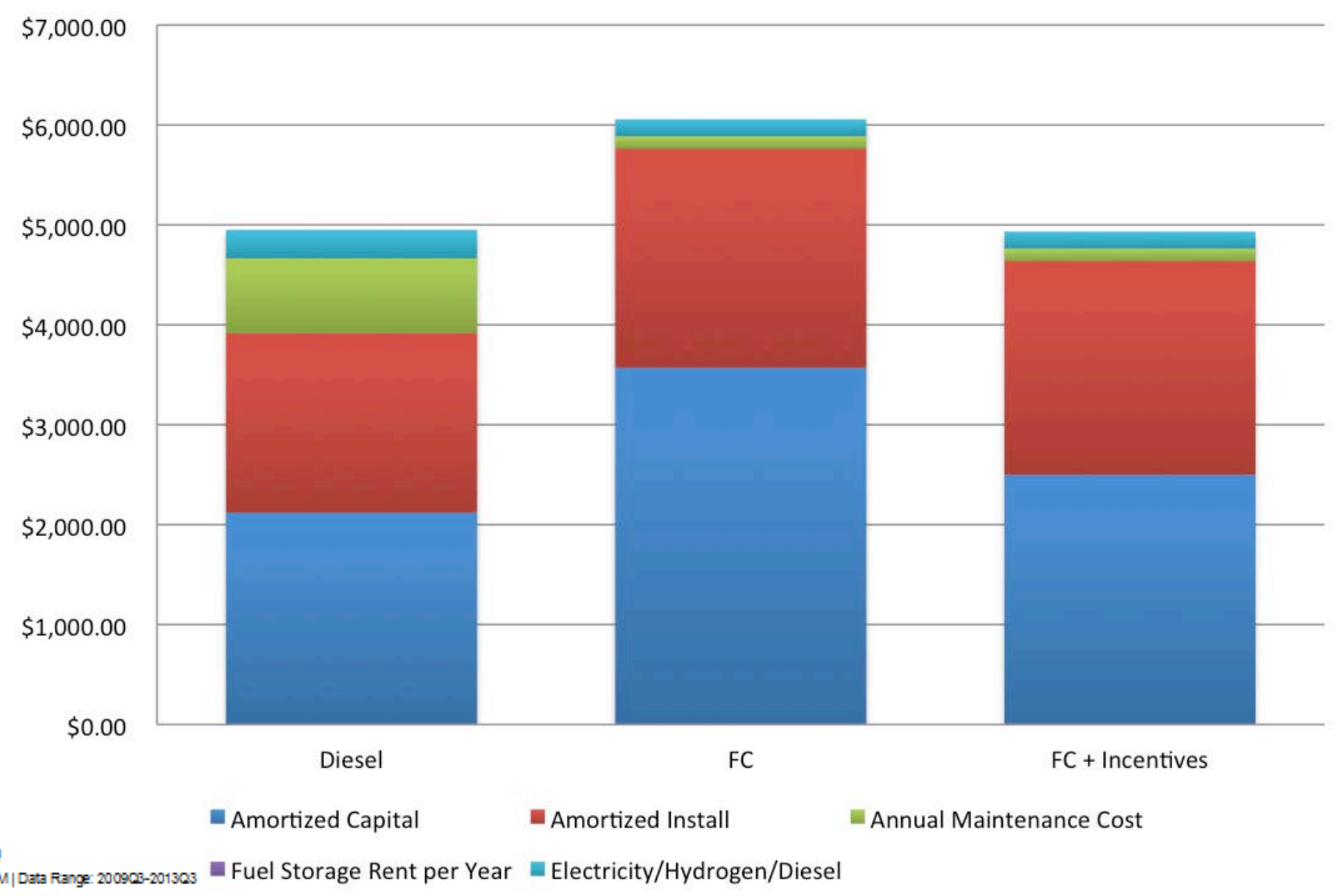




\section{2-hour Annualized Cost of Ownership}

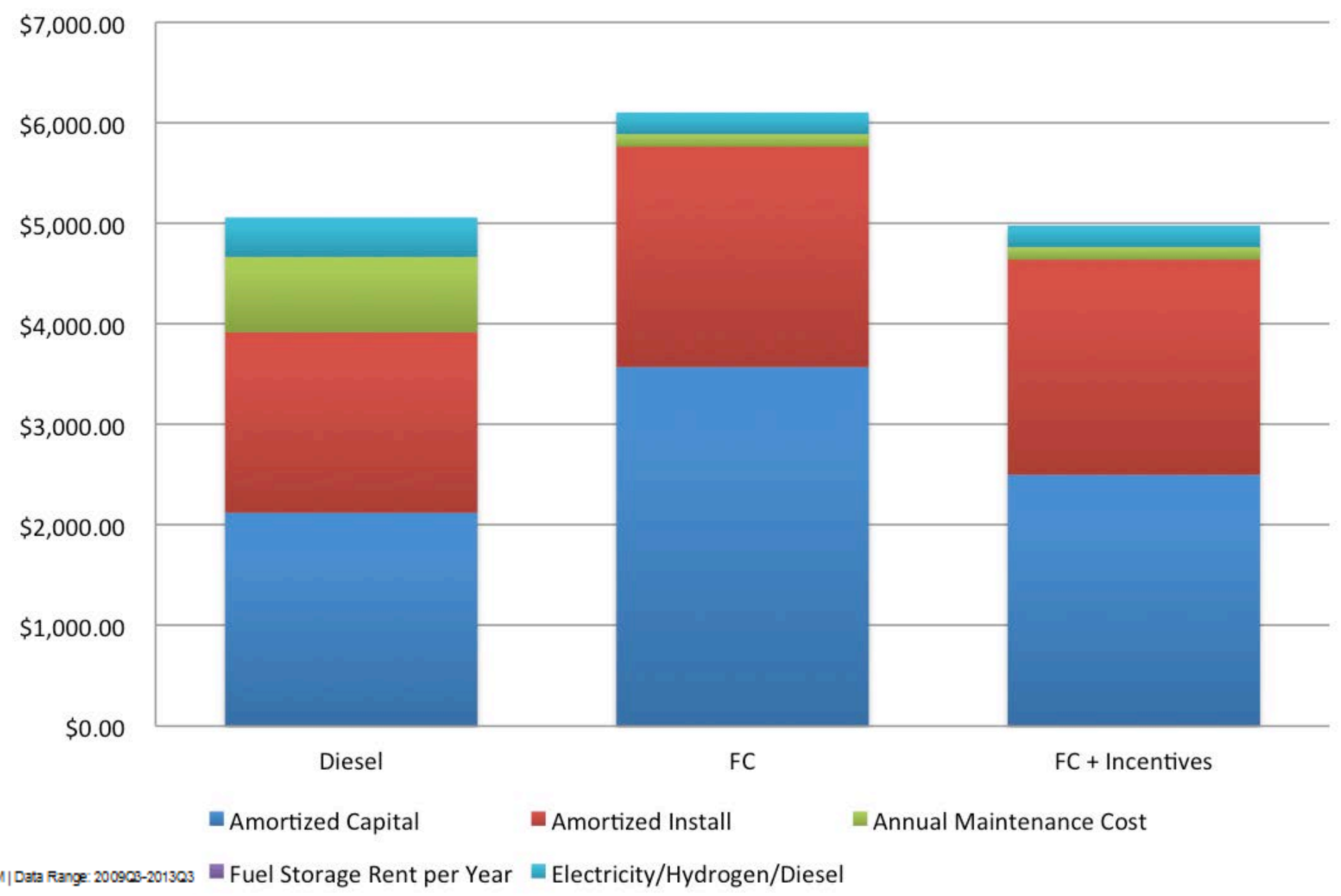




\section{6-hour Annualized Cost of Ownership}

\section{6-hour Annualized Cost of Ownership}

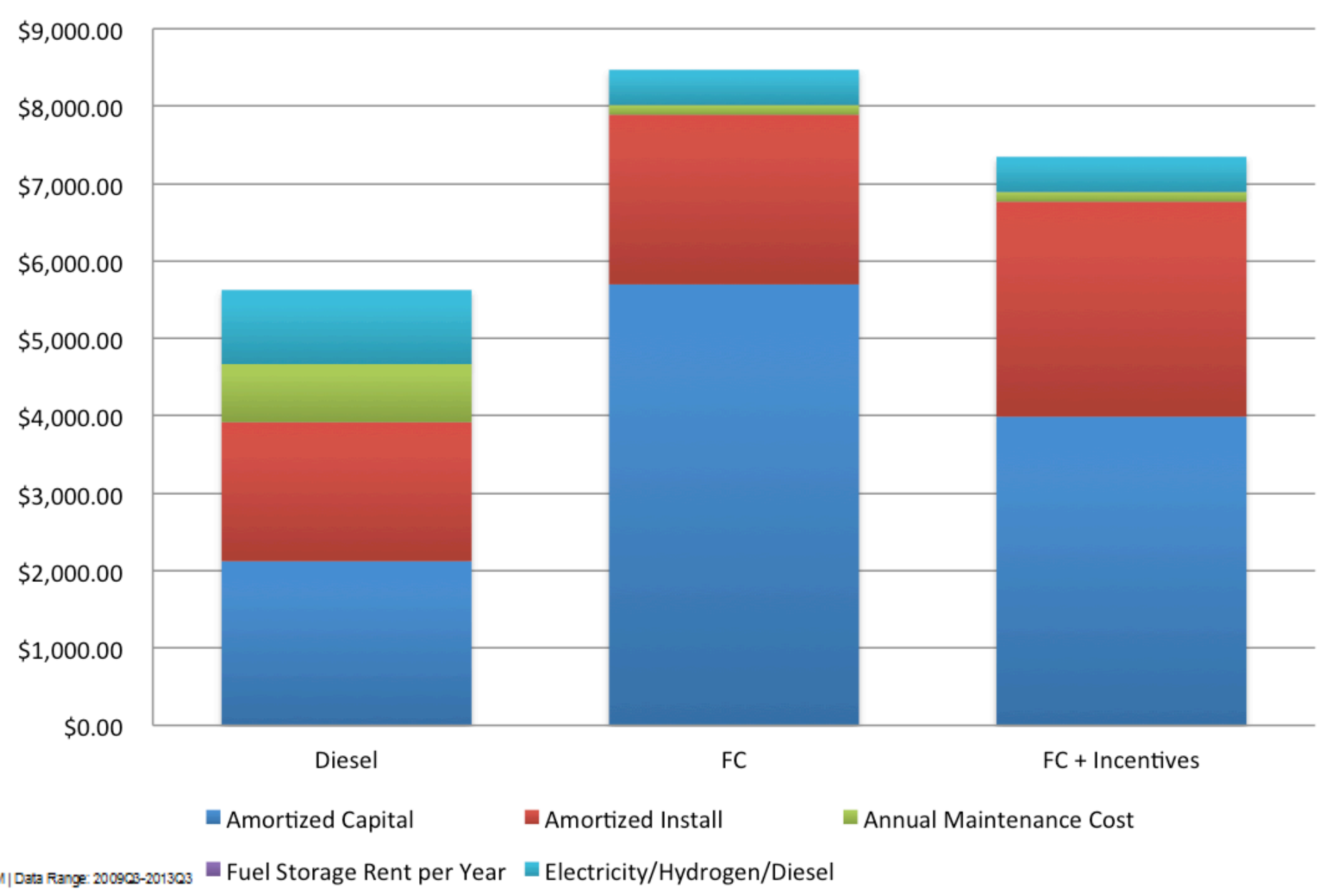




\section{Annualized Cost of Ownership Heat Map}
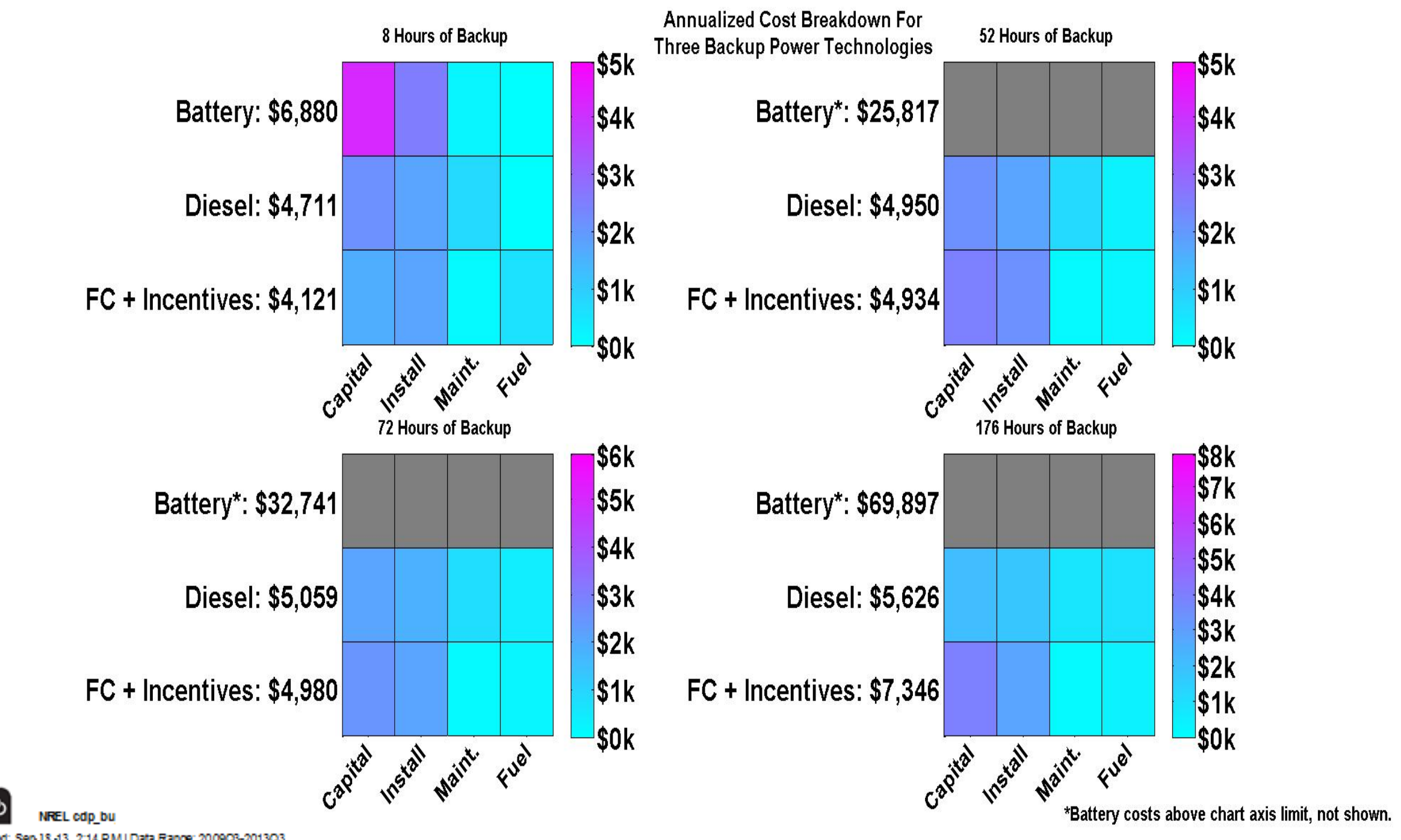